\title{
Attention Deficit/Hyperactivity Disorder and risk for non- affective psychotic disorder: The role of ADHD medication and comorbidity, and sibling comparison.
} DOI:

10.1016/j.schres.2020.01.021

\section{Document Version}

Accepted author manuscript

Link to publication record in Manchester Research Explorer

Citation for published version (APA):

Pierce, M. (2020). Attention Deficit/Hyperactivity Disorder and risk for non-affective psychotic disorder: The role of ADHD medication and comorbidity, and sibling comparison. Schizophrenia Research. https://doi.org/10.1016/j.schres.2020.01.021

Published in:

Schizophrenia Research.

\section{Citing this paper}

Please note that where the full-text provided on Manchester Research Explorer is the Author Accepted Manuscript or Proof version this may differ from the final Published version. If citing, it is advised that you check and use the publisher's definitive version.

\section{General rights}

Copyright and moral rights for the publications made accessible in the Research Explorer are retained by the authors and/or other copyright owners and it is a condition of accessing publications that users recognise and abide by the legal requirements associated with these rights.

\section{Takedown policy}

If you believe that this document breaches copyright please refer to the University of Manchester's Takedown Procedures [http://man.ac.uk/04Y6Bo] or contact uml.scholarlycommunications@manchester.ac.uk providing relevant details, so we can investigate your claim.

\section{OPEN ACCESS}




\title{
Attention Deficit/Hyperactivity Disorder and risk for non-affective psychotic disorder: The role of ADHD medication and comorbidity, and sibling comparison
}

\author{
Emma Björkenstam ${ }^{\text {a,b,c,*, Matthias Pierce }}{ }^{\mathrm{d}}$, Charlotte Björkenstam ${ }^{\mathrm{c}}$, Christina Dalman ${ }^{\text {e,f }}$, Kyriaki Kosidou ${ }^{\text {e,f }}$ \\ a Department of Clinical Neuroscience, Division of Insurance Medicine, Karolinska Institutet, Stockholm, Sweden \\ ${ }^{\mathrm{b}}$ Department of Community Health Sciences, Fielding School of Public Health and California Center for Population Research, University of California Los Angeles, Los Angeles, CA, United States \\ c Department of Neuroscience, Psychiatry, Uppsala University, Uppsala, Sweden \\ ' Center for Women's Mental Health, School of Health Sciences, University of Manchester, UK \\ e Department of Public Health Sciences, Division Public Health Epidemiology, Karolinska Institutet, Stockholm, Sweden \\ ${ }^{\mathrm{f}}$ Center for Epidemiology and Community Medicine, Stockholm County Council, Stockholm, Sweden
}

\section{A R T I C L E I N F O}

\section{Article history:}

Received 13 October 2019

Received in revised form 16 January 2020

Accepted 19 January 2020

Available online $\mathrm{xxxx}$

\section{Keywords:}

Attention Deficit/Hyperactivity Disorder

Non-Affective psychotic disorder

Cohort

Sweden

Epidemiology

\begin{abstract}
A B S T R A C T
Attention Deficit/Hyperactivity Disorder (ADHD) is the most common psychiatric disorder in childhood. It is unclear whether ADHD increases the risk of non-affective psychotic disorder (NAPD). The study included a matched cohort, drawn from all born in Sweden 1987-1991 $(\mathrm{n}=548,852)$. ADHD was defined as ICD diagnosis and/or prescription of ADHD medication. We distinguished between stimulants and non-stimulants, and usage duration ( $<1$ year, $1-2$ years and $\geq 2$ years). We calculated odds ratios (OR) with $95 \%$ confidence intervals $(C I)$ for NAPD, adjusted for confounders, comorbid autism spectrum disorder (ASD) and substance abuse. ADHD cases were also compared to their unaffected full siblings. We analyzed 18,139 ADHD cases and 72,437 sex and birth year matched controls. NAPD was more common in cases than controls ( 2.7 and $0.4 \%$, respectively). After adjustment for confounders, ADHD cases had markedly high risk for NAPD (OR: 6.99; 95\% CI 6.03-8.10), which attenuated further after adjustment for ASD and substance abuse (OR: 2.57; 95\% CI 2.09-3.16). Utilization of ADHD medication increased the risk for NAPD (ORs for change in odds of NAPD for every 5 extra prescriptions of stimulants 1.06 (95\% CI 1.02-1.10) and, non-stimulants 1.15 (95\% CI 1.01-1.30)). There was no association between usage length of medication and risk for NAPD. The risk was higher in individuals with ADHD than their unaffected siblings (OR: 2.95 (95\% CI 2.07-4.20)). Overall, ADHD was associated with elevated risk for NAPD, which is not entirely explained by shared familial factors. The clinical severity leading to medical treatment may also increase NAPD risk.
\end{abstract}

Ethics approval: Approved by the ethical committee in Stockholm, Sweden (dnrs: 2010-1185-31/5 and 2013/ 1118-32)

(C) 2020 Published by Elsevier B.V.

\section{Introduction}

Attention-deficit/hyperactivity disorder (ADHD) is a neurodevelopmental disorder characterized by developmentally inappropriate and impaired levels of attention and/or hyperactivity and impulsivity (Biederman and Faraone, 2005). ADHD is the most common childhood mental disorder, affecting approximately $7 \%$ of school-aged children worldwide (Biederman and Faraone, 2005; Thomas et al., 2015).

According to treatment guidelines, pharmacological treatment of ADHD should be considered in patients when symptoms are insufficiently controlled by non-pharmacological interventions (Zetterqvist

\footnotetext{
* Corresponding author at: Department of Clinical Neuroscience, Division of Insurance Medicine, Karolinska Institutet, SE-171 77 Stockholm, Sweden.

E-mail address: emma.bjorkenstam@ki.se (E. Björkenstam).
}

et al., 2013). The majority ( $\approx 70 \%$ ) of patients with ADHD receive pharmacological treatment (Giacobini et al., 2018; Zuvekas and Vitiello, 2012). The most widely used drugs to treat ADHD are stimulants (derived from methylphenidate or amphetamine) and non-stimulant medications (e.g. atomoxetine) (Zetterqvist et al., 2013; Zuvekas and Vitiello, 2012). The number of prescriptions dispensed for ADHD drugs have increased substantially over recent years (Bahmanyar et al., 2013; Mosholder et al., 2009; Zetterqvist et al., 2013; Zuvekas and Vitiello, 2012).

It is estimated that about two thirds of individuals with ADHD have a comorbid mental disorder, such as mood, anxiety and sleep disorders (Leitner, 2014), Autism Spectrum Disorder (ASD), and substance abuse (Capusan et al., 2019; Giacobini et al., 2018). Further, some studies have indicated that patients with ADHD might have increased risk for schizophrenia and other non-affective psychotic disorders (NAPD) 
(Brodsky et al., 2014; MacKenzie et al., 2016; Shyu et al., 2015). These studies have yielded considerable heterogeneity in the strength of the association, which might be due to small or non-representative samples (Brodsky et al., 2014; MacKenzie et al., 2016; Moran et al., 2015; Mosholder et al., 2009), the inability to differentiate between different NAP disorders (Mosholder et al., 2009), and short follow-up periods (MacKenzie et al., 2016). One study failed to find an association between ADHD and risk for NAPD (Vitiello et al., 2017). Moreover, our understanding of why ADHD might increase risk for NAPD is limited.

For example, children with ASD are known to have a markedly high risk for NAPD (Selten et al., 2015), and comorbidity between ASD and ADHD could explain the elevated risk for NAPD in ADHD. Substance abuse disorders are another major comorbidity in ADHD, and may increase risk for NAPD (Colizzi and Murray, 2018). Yet, no study has examined whether comorbidity with substance abuse and/or ASD explains risk for NAPD in ADHD.

Some studies have indicated that stimulant medications, which may induce psychotic symptoms when abused, might increase risk for NAPD in treated patients (MacKenzie et al., 2016; Shyu et al., 2015). Yet, other studies do not support this notion (Man et al., 2016). A recent study found stimulants use to be associated with earlier onset of psychosis (Moran et al., 2015). Given the worldwide rise in prescriptions dispensed for ADHD, the question whether ADHD medications, and stimulants in particular, increase the risk for NAPD is important and warrants further research (MacKenzie et al., 2016; Moran et al., 2015; Shyu et al., 2015).

In light of the deleterious effects psychotic disorders may have, it is important to clarify whether ADHD increases the risk of NAPD, and whether there are risk and protective factors. The current study used a matched cohort drawn from a sample of nearly 550,000 individuals born between 1987 and 1991, to examine the risk for NAPD, including schizophrenia, among patients with ADHD compared to healthy individuals. Additionally, we investigated whether type of (i.e. stimulants vs. non-stimulants) and length of ADHD medication usage affects the risk for NAPD in ADHD patients, and whether the association is explained by comorbid ASD and/or substance abuse. Last, psychiatric disorders have been found to co-occur in families, including ADHD and NAPD (Larsson et al., 2013). To examine the role of familial confounding, we compared the risk for NAPD between patients with ADHD and their non-affected siblings.

\section{Methods}

The unique personal identity number, assigned to each Swedish citizen or permanent resident, was used to link information from several population-based registers in a comprehensive linkage called Psychiatry Sweden:

The Medical Birth Register (MBR) includes data on all deliveries in Sweden since 1973. The National Patient Register (NPR) has collected all inpatient medical data in Sweden since 1973, and specialized outpatient care since 2001. The Causes of Death Register comprises information on all deaths of Swedish residents since 1952. The Total Population Register includes information on age, sex, place of residence, and other demographic characteristics. The Longitudinal Integration Database for Health Insurance and Labor Market Studies (LISA) integrates existing data from the labor market, and from the educational and social sectors. Families were linked together through the MultiGeneration register, which contains all known relationships between children and parents since 1961. Finally, the Prescribed Drug Register (PDR) contains patient identities for all dispensed prescribed drugs (grouped according to the Anatomical Therapeutic Chemical Classification System (ATC)) to the entire Swedish population since July 2005.

This study was reviewed and approved by the regional ethical review board of Stockholm (dnrs: 2010-1185-31/5 and 2013/1118-32). In accordance with the Swedish Personal Data Act of 1998 (http:// www.datainspektionen.se/in-english/legislation/the-personal-data- act/) and the decision of the ethical review board, we did not obtain informed consent from the study participants. All study data were anonymized.

\subsection{Exposure}

We used a validated two-step approach to identify subjects exposed to ADHD (Skoglund et al., 2015). First, ADHD exposure status was defined as a recorded diagnosis of ICD-9: 314 or ICD-10: F90 in the NPR between birth and December 31st 2014. Second, from the PDR we obtained information on the following prescribed drugs: stimulant medication (amphetamine (ATC: N06BA01), dexamphetamine (ATC: N06BA02), and methylphenidate (ATC: N06BA04)), and nonstimulant medication (atomoxetin (ATC: N06BA09)). An individual was considered to have received drug treatment if at least one prescription was dispensed between July 1, 2005-December 31, 2014. To calculate the medication length, we counted the number of previous stimulant and, respectively, non-stimulant prescriptions. The length was calculated as the last prescription minus the first one, and categorized as $<1$ year, $1-<2$ years, $\geq 2$ years.

\subsection{Study design}

The matched study cohort was selected from all individuals born in Sweden between 1987 and $1991(\mathrm{n}=571,797)$. We excluded all who died $(n=4459)$, emigrated $(n=17,952)$ or had a NAPD diagnosis ( $n$ $=82$ ) prior to age 15 . The final cohort comprised 549,011 individuals (Fig. 1).

Following this selection, individuals exposed to ADHD were matched on birth year and sex (without replacement) to up to four people unexposed to ADHD. Each matched group was followed-up from the age of earliest ADHD diagnosis and/or ADHD medication prescription for the exposed subject to the end of data collection (December $312,016)$. Exposed and unexposed subjects were excluded if they had a NAPD diagnosis prior to them starting follow-up ( $\mathrm{n}=296$ and 122 respectively). The matched design ensures that exposed and unexposed people in the same matched group were followed up from the same date and that exclusion criteria was applied evenly to both.

In order to investigate the effect of ADHD stimulant and nonstimulant medications, we conducted a nested case-control analysis using ADHD exposed individuals only restricted to those whose first recorded instance of ADHD (in either the inpatient, outpatient or medicine registries) was from 2006 onwards $(\mathrm{N}=13,237)$ i.e. after the start of the PDR. Using this sub-cohort, we matched NAPD cases ( $\mathrm{N}=$ 492) with four non-NAPD controls, using exact matches. The date when the case developed NAPD became an index date and we looked back at the history of stimulant and non-stimulant prescriptions.

\subsection{Outcome}

NAPD was defined as a registered main diagnosis of psychosis (ICD9: 295, 297-298; ICD-10: F20-29) in the NPR during follow-up. We only considered NAPD diagnoses occurring from age 15 years until December 31, 2016 (i.e. those born in 1987 were followed for a maximum of 14 years, and those born in 1991 for a maximum of 10 years). Additionally, we examined schizophrenia and other NAPD diagnoses separately.

\subsection{Sibling controls}

Using the Multi-Generation Register, we identified individuals with ADHD who also had one or more full siblings without ADHD. We only included those with at least one unaffected full sibling, alive at age 15, born no later than 1994 and not before 1984 (to be comparable regarding age to their affected siblings). The total sample for these sibling analyses included 14,787 individuals with ADHD and 14,787 unaffected full siblings. 


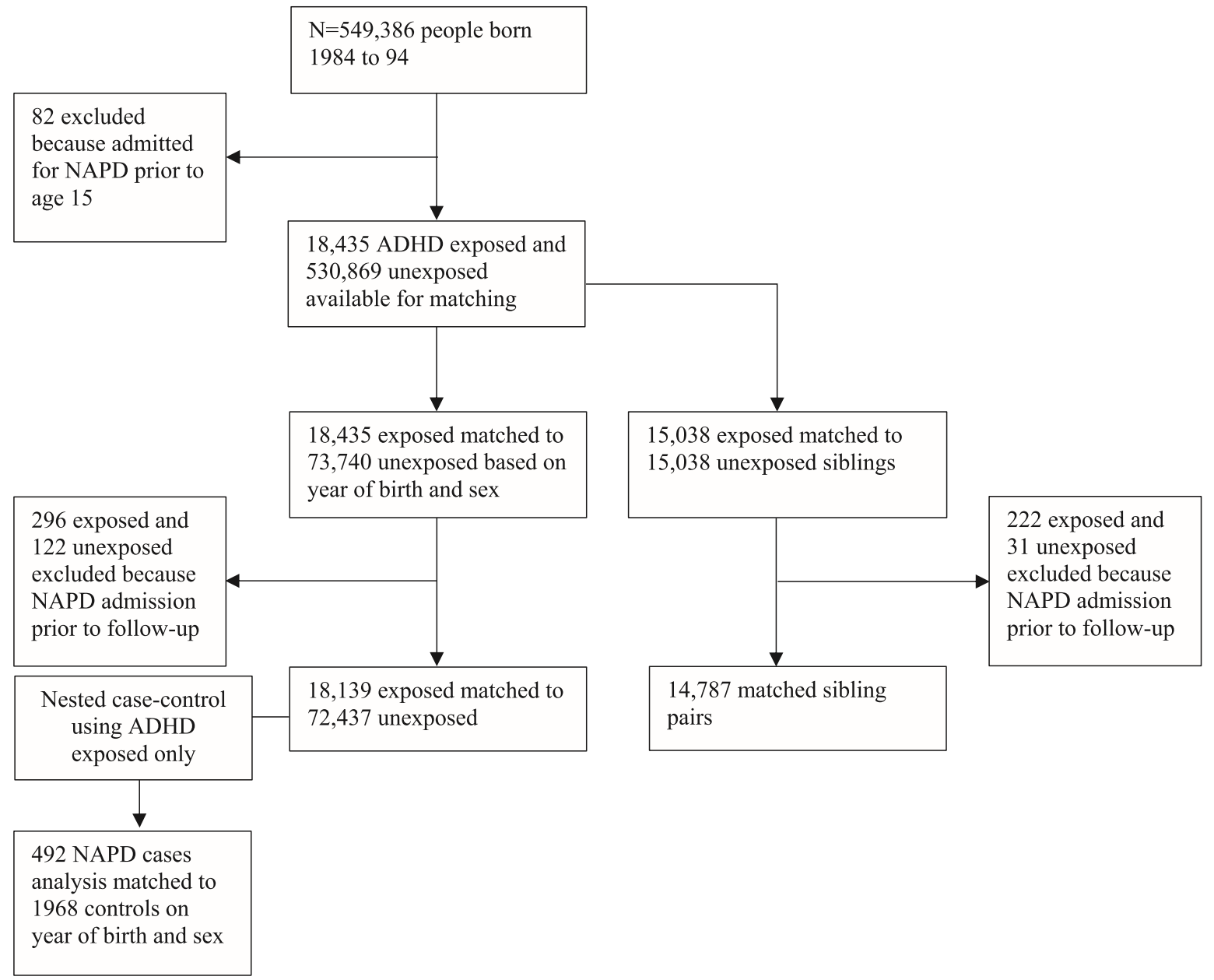

Fig. 1. Flow chart detailing selection of matched cohorts.

\subsection{Covariates}

In addition to matching on sex and year of birth, we controlled for known risk factors for NAPD. Highest parental education was classified as compulsory school or less (9 years maximum), secondary school (10-12 years), and university/college (13+ years). We also controlled for parental NAPD and other psychiatric disorders, diagnosed between date of child's birth and 2016, and birth country of parents (Sweden or other). Place of birth, a proxy for urban upbringing, was captured at the time of the child's birth and was classified into three categories: small (rural municipalities), intermediate $(>90,000$ inhabitants), and big city area (the three large city areas in Sweden). Last, from the NPR, we obtained information on the following comorbid psychiatric disorders: ASD (ICD-9: 299; ICD-10: F84), and substance abuse (ICD-9: 291,292,303-305; ICD-10: F10-19).

\subsection{Statistical analyses}

We used conditional binary logistic regression to evaluate the associations between ADHD and first-episode NAPD, presented as odds ratios (OR) with $95 \%$ confidence intervals (CI). These were conditional on the matched group, to account for clustering by the matched design. Five regression models were reported: Model I adjusted for sex and birth year, and Model II also for sociodemographic and other background confounders, including place of birth, parental country of birth, parental education, parental psychosis and parental other psychiatric disorder. Both ASD and substance misuse were considered to be potentially on the causal pathway between ADHD and NAPD, therefore we reported models with additional adjustment for ASD (Model III), substance misuse (Model IV) and both (Model V). When analyzing medication length, we conducted conditional logistic regression to look at the effect of both number of previous prescriptions and length. For sibling analyses, we also used conditional logistic regression for matched pair data (Model I adjusted for birth year and sex and Models II-IV further adjusted for ASD and substance abuse).

\section{Results}

The total matched cohort included 18,139 individuals with ADHD and 72,437 unexposed (Table 1). Parents of individuals with ADHD more often had a history of a psychiatric disorder, and less favorable socioeconomic characteristics than parents of the controls. Twenty-six percent of individuals with ADHD had comorbid substance abuse (but only $5.0 \%$ of controls), of which the most common was alcohol-related disorders ( $11.9 \%$ of individuals with ADHD vs. $3.3 \%$ of controls). Other substance abuse disorders observed were cocaine or amphetamines ( $1.2 \%$ vs. $0.3 \%$ ) and opioids ( $1.2 \%$ vs. $0.1 \%$ ) (data not shown). Among those with ADHD, $14 \%$ had comorbid ASD (but only $1.2 \%$ of controls). Among controls, $0.4 \%(n=290)$ individuals retrieved a diagnosis for NAPD during the follow-up period. The proportion was higher among individuals with $\operatorname{ADHD}(2.7 \%, \mathrm{n}=492)$.

Individuals with ADHD had markedly high OR for NAPD (6.99 (95\% CI 6.03-8.10) in Model I) compared to controls (Table 2). In Model II, the ORs decreased slightly. When additional adjustments were made for comorbid ASD and substance abuse, all ORs decreased markedly 
Table 1

Matched cohort characteristics. Absolute numbers and column percentage.

\begin{tabular}{|c|c|c|}
\hline \multirow[t]{2}{*}{ Characteristics } & \multirow{2}{*}{$\begin{array}{l}\text { Individuals } \\
\text { with } \\
\text { ADHD } \\
18,139(100)\end{array}$} & \multirow{2}{*}{$\begin{array}{l}\text { Unexposed } \\
\text { matched } \\
\text { controls } \\
72,437(100)\end{array}$} \\
\hline & & \\
\hline \multicolumn{3}{|l|}{ Sex } \\
\hline Females & $10,925(60.2)$ & $43,631(60.2)$ \\
\hline Males & $7214(39.8)$ & $28,806(39.8)$ \\
\hline \multicolumn{3}{|l|}{ Place of birth } \\
\hline Small (rural municipalities) & $5226(28.8)$ & $22,901(31.6)$ \\
\hline Intermediate ( $>90,000$ inhabitants) & $6038(33.3)$ & $25,215(34.8)$ \\
\hline Big city area & $6849(37.8)$ & $24,246(33.5)$ \\
\hline Missing & $26(0.1)$ & $75(0.1)$ \\
\hline \multicolumn{3}{|l|}{ Parental educational level } \\
\hline 9 years of education & $2328(12.8)$ & $5940(8.2)$ \\
\hline $10-12$ years of education & $11,279(62.2)$ & $40,397(55.8)$ \\
\hline$>12$ years of education & $4463(24.6)$ & $25,802(35.6)$ \\
\hline Missing & $69(0.4)$ & $298(0.4)$ \\
\hline Parent(s) born outside of Sweden & $913(5.0)$ & $4844(6.7)$ \\
\hline Parental history of NAPD & $483(2.7)$ & $1043(1.4)$ \\
\hline $\begin{array}{l}\text { Parental history of other psychiatric } \\
\text { disorder }\end{array}$ & $8469(46.7)$ & $17,229(23.8)$ \\
\hline \multicolumn{3}{|l|}{ Comorbid psychiatric diagnoses } \\
\hline Autism spectrum disorder (ASD) & $2613(14.4)$ & $833(1.2)$ \\
\hline Substance abuse disorder & $4826(26.6)$ & $3644(5.0)$ \\
\hline
\end{tabular}

Numbers in brackets represent column percentages.

(Table 2, Models III-V). Thus, the risk for NAPD in ADHD was largely explained by comorbid ASD, and/or substance abuse. In the multi-adjusted model (Model V), individuals with ADHD still had an over two-fold increased risk for NAPD, compared to controls (OR: 2.57 (95\% CI 2.09-3.16)). ORs were similar for schizophrenia and other NAPD.

Table 3 presents the results from examining effects of ADHD stimulant and non-stimulant medication on NAPD in the sub-cohort of 13,237 individuals, identified as having ADHD from 2006 and onwards. Utilization of medication was associated with increased risk for NAPD, compared to ADHD individuals not on medication. The ORs for change in odds of NAPD for every 5 extra prescriptions of stimulants were 1.06 (95\% CI 1.02-1.10), and somewhat higher for non-stimulants (OR: 1.15 (95\% CI 1.01-1.30)). In the analysis of length of medication usage in relation to NAPD risk, estimates were higher for shorter usage ( $<1$ year), compared to longer usage $(1-<2$ years and, respectively, $\geq 2$ years). This was true for both stimulant and non-stimulant medication. However, Cls for longer usage of either medication were wide and lack of statistical power limited this analysis. Only $1.1 \%$ of people with ADHD had a prescription for amphetamines, $70.7 \%$ for methylphenidate. There was no evidence of a relationship between receiving either amphetamines or methylpenidate and subsequent NAPD ( $\mathrm{p}=$ .19 and 0.30 respectively) (data not shown).
The sibling analyses included 14,787 individuals with ADHD and their unaffected siblings. When compared to their unaffected siblings (Table 4), individuals with ADHD evidenced higher risk for NAPD (OR, 5.04 (95\% CI 3.78-6.73)), when adjustments were made for sex and birth year. When we controlled for comorbid ASD and substance abuse, the OR decreased but remained significant (OR $2.95(95 \% \mathrm{Cl}$ 2.07-4.20)).

\section{Discussion}

\subsection{Key results}

In this large matched cohort study of 18,139 individuals with ADHD and 72,437 unexposed matched controls, we found that individuals with ADHD were at higher risk for NAPD, including schizophrenia and other NAPD. The risk was attenuated, but remained significant, when comorbidity with ASD and substance abuse, which have been associated with increased risk for NAPD, were taken into account. After adjustments for confounders and comorbidity, individuals with ADHD had an over two-fold risk for NAPD. Among individuals with ADHD, usage of either stimulant or non-stimulant medication was associated with increased risk for NAPD. The risk was unrelated to longer duration of medication. These findings indicate that the clinical severity that lead to pharmacological treatment in ADHD may increase risk for NAPD. Lastly, individuals with ADHD had higher risk for NAPD than their unaffected full siblings, indicating that shared familial liability does not entirely explain the risk for NAPD in ADHD.

\subsection{Strengths and limitations}

This study has several strengths, including the population-based design, large size and use of high quality national registers with limited loss to follow up. However, there are limitations. We only had information on specialized outpatient care from 2001 and onwards and data on medical treatment from July 2005 and onwards. This might have led to misclassification of ADHD cases as controls (due to missing in outpatient and medication data) and, therefore, a dilution of the association between ADHD and NAPD. It could also mean that we capture more severe cases of ADHD, such as those treated in inpatient care, at the beginning of the follow- up period i.e. before the start of outpatient and medication data. However, ADHD was yet an uncommon diagnosis before the early 2000ies in Sweden (Giacobini et al., 2018) as well as in many other countries (Polanczyk et al., 2014), as reflected in the number of diagnosed cases each calendar year in our study population. Also, ADHD is a chronic condition and individuals with ADHD are likely to have many encounters with the health care system and thereby be captured in the NPR at some time point during later years. Hence, we

Table 2

Associations between ADHD and first episode NAPD. Odds ratios with 95\% confidence intervals.

\begin{tabular}{|c|c|c|c|c|c|c|c|}
\hline & No of individuals & No with NAPD (\%) & Model I ${ }^{\mathrm{a}}$ & Model II ${ }^{\mathrm{b}}$ & Model III $^{c}$ & Model IV ${ }^{d}$ & Model V \\
\hline \multicolumn{8}{|l|}{ NAPD } \\
\hline No ADHD & 72,437 & $290(0.4)$ & 1 (REF) & 1 (REF) & 1 (REF) & 1 (REF) & 1 (REF) \\
\hline ADHD & 18,139 & $492(2.7)$ & $6.99(6.03-8.10)$ & $6.37(5.44-7.47)$ & $5.14(4.35-6.07)$ & $3.65(3.02-4.40)$ & $2.57(2.09-3.16)$ \\
\hline \multicolumn{8}{|c|}{ Schizophrenia } \\
\hline No ADHD & 72,437 & $49(0.1)$ & 1 (REF) & 1 (REF) & 1 (REF) & 1 (REF) & 1 (REF) \\
\hline ADHD & 18,139 & $76(0.4)$ & $6.20(4.33-8.88)$ & $5.83(3.95-8.61)$ & $4.49(2.91-6.92)$ & $4.16(2.71-6.40)$ & $2.84(1.73-4.66)$ \\
\hline \multicolumn{8}{|c|}{ Other NAPD } \\
\hline No ADHD & 72,437 & $241(0.3)$ & 1 (REF) & 1 (REF) & 1 (REF) & 1 (REF) & 1 (REF) \\
\hline ADHD & 18,139 & $416(2.3)$ & $7.12(6.06-8.36)$ & $6.44(5.41-7.66)$ & $5.26(4.39-6.31)$ & $3.49(2.83-4.30)$ & $2.50(1.99-3.15)$ \\
\hline
\end{tabular}

a Unadjusted (except matched for sex, age and birth year).

b Model I with additional adjustments for place of birth, parental country of birth, parental education, and parental history of NAPD or other psychiatric disorder.

c Model II with additional adjustments for ASD.

d Model II with additional adjustments for substance abuse.

e Model II with additional adjustments for ASD and substance abuse. 
Table 3

Associations between stimulant and non-stimulant ADHD medication and first episode NAPD. Odds Ratios (OR) with 95\% confidence intervals (CI).

\begin{tabular}{|c|c|c|c|c|c|c|c|}
\hline Variable & $\begin{array}{l}\text { NAPD Cases, mean } \pm S D \\
\text { or } \\
\mathrm{N}(\%)\end{array}$ & $\begin{array}{l}\text { Controls, mean } \pm \text { SD or } \\
\mathrm{N} \\
(\%)\end{array}$ & Model I ${ }^{\mathrm{a}}$ & Model II ${ }^{\mathrm{b}}$ & Model III ${ }^{\mathrm{C}}$ & Model IV ${ }^{\mathrm{d}}$ & Model Ve \\
\hline Number of stimulant prescriptions ${ }^{f}$ & $10.3 \pm 17.5$ & $6.9(12.0)$ & $\begin{array}{l}1.08 \\
(1.05-1.12)\end{array}$ & $\begin{array}{l}1.09 \\
(1.05-1.12)\end{array}$ & $\begin{array}{l}1.08 \\
(1.04-1.11)\end{array}$ & $\begin{array}{l}1.07 \\
(1.03-1.11)\end{array}$ & $\begin{array}{l}1.06 \\
(1.02-1.10)\end{array}$ \\
\hline $\begin{array}{l}\text { Number of non-stimulant } \\
\text { prescriptions }^{f}\end{array}$ & $1.5 \pm 3.9$ & $0.9(4.0)$ & $\begin{array}{l}1.16 \\
(1.04-1.29)\end{array}$ & $\begin{array}{l}1.15 \\
(1.03-1.29)\end{array}$ & $\begin{array}{l}1.14 \\
(1.02-1.27)\end{array}$ & $\begin{array}{l}1.17 \\
(1.03-1.32)\end{array}$ & $\begin{array}{l}1.15 \\
(1.01-1.30)\end{array}$ \\
\hline \multicolumn{8}{|l|}{ Duration of stimulant prescriptions } \\
\hline Not on & $171(35)$ & $893(45)$ & 1 (REF) & 1 (REF) & 1 (REF) & 1 (REF) & 1 (REF) \\
\hline$<1$ year & $153(31)$ & $481(24)$ & $\begin{array}{l}2.60 \\
(1.98-3.41)\end{array}$ & $\begin{array}{l}2.57 \\
(1.95-3.40)\end{array}$ & $\begin{array}{l}2.61 \\
(1.97-3.45)\end{array}$ & $\begin{array}{l}2.11 \\
(1.56-2.85)\end{array}$ & $\begin{array}{l}2.16 \\
(1.59-2.93)\end{array}$ \\
\hline $1-2$ years & $44(9)$ & $172(9)$ & $\begin{array}{l}1.85 \\
(0.93-3.67)\end{array}$ & $\begin{array}{l}1.83 \\
(0.90-3.69)\end{array}$ & $\begin{array}{l}1.79 \\
(0.87-3.66)\end{array}$ & $\begin{array}{l}1.80 \\
(0.83-3.92)\end{array}$ & $\begin{array}{l}1.79 \\
(0.82-3.89)\end{array}$ \\
\hline$\geq 2$ years & $124(25)$ & $422(21)$ & $\begin{array}{l}1.84 \\
(0.92-3.66)\end{array}$ & $\begin{array}{l}1.87 \\
(0.93-3.77)\end{array}$ & $\begin{array}{l}1.72 \\
(0.84-3.50)\end{array}$ & $\begin{array}{l}1.68 \\
(0.78-3.63)\end{array}$ & $\begin{array}{l}1.49 \\
(0.67-3.30)\end{array}$ \\
\hline \multicolumn{8}{|l|}{$\begin{array}{l}\text { Duration of non-stimulant } \\
\text { prescriptions }\end{array}$} \\
\hline Not on & $361(73)$ & $1722(88)$ & 1 (REF) & 1 (REF) & 1 (REF) & 1 (REF) & 1 (REF) \\
\hline$<1$ year & $107(22)$ & $184(9)$ & $\begin{array}{l}1.54 \\
(1.19-1.98)\end{array}$ & $\begin{array}{l}1.51 \\
(1.16-1.95)\end{array}$ & $\begin{array}{l}1.50 \\
(1.16-1.95)\end{array}$ & $\begin{array}{l}1.53 \\
(1.16-2.02)\end{array}$ & $\begin{array}{l}1.53 \\
(1.15-2.03)\end{array}$ \\
\hline $1-2$ years & $12(2)$ & $31(2)$ & $\begin{array}{l}1.26 \\
(0.86-1.84)\end{array}$ & $\begin{array}{l}1.20 \\
(0.81-1.77)\end{array}$ & $\begin{array}{l}1.18 \\
(0.79-1.74)\end{array}$ & $\begin{array}{l}1.14 \\
(0.75-1.73)\end{array}$ & $\begin{array}{l}1.14 \\
(0.74-1.74)\end{array}$ \\
\hline$\geq 2$ years & $12(2)$ & $31(2)$ & $\begin{array}{l}1.41 \\
(1.07-1.84)\end{array}$ & $\begin{array}{l}1.45 \\
(1.10-1.90)\end{array}$ & $\begin{array}{l}1.38 \\
(1.04-1.82)\end{array}$ & $\begin{array}{l}1.36 \\
(1.01-1.84)\end{array}$ & $\begin{array}{l}1.25 \\
(0.92-1.70)\end{array}$ \\
\hline
\end{tabular}

a Adjusted for sex and birth year.

b Model I with additional adjustments for place of birth, parental country of birth, parental education, and parental history of NAPD or other psychiatric disorder.

c Model II with additional adjustments for ASD.

d Model II with additional adjustments for substance abuse.

e Model II with additional adjustments for ASD and substance abuse.

${ }^{f}$ OR represents change in odds of NAPD for every 5 extra prescriptions of stimulants/non-stimulants

are likely to have captured a majority of the individuals with diagnosed ADHD in our study population. Nevertheless, we have misclassified individuals diagnosed in childhood only who stopped receiving medical treatment by $10-14$ years of age as unexposed. Further, we identified ADHD and NAPD cases based on records of diagnoses and prescribed medications, which may only reflect the time at diagnosis or treatment rather than time at actual onset of the disease. In order to better assess the association between ADHD and NAPD, detailed data on the occurrence and progression of the conditions is required. Information on substance abuse relied solely on register data therefore we likely captured only the most severe cases. We distinguished between shorter versus longer usage length of ADHD medication without finding any obvious trend regarding

Table 4

Odds ratios (OR) with 95\% confidence intervals for first-episode NAPD, comparing 14,787 ADHD cases with their unaffected full siblings.

\begin{tabular}{|c|c|c|c|c|}
\hline & Model I ${ }^{a}$ & Model II ${ }^{\mathrm{b}}$ & Model III ${ }^{\mathrm{c}}$ & Model IV ${ }^{\mathrm{d}}$ \\
\hline \multicolumn{5}{|l|}{ NAPD } \\
\hline $\begin{array}{l}\text { No ADHD (unaffected } \\
\text { siblings) }\end{array}$ & 1 (REF) & 1 (REF) & 1 (REF) & 1 (REF) \\
\hline ADHD & $\begin{array}{l}5.04 \\
(3.78-6.73)\end{array}$ & $\begin{array}{l}4.47 \\
(3.33-6.00)\end{array}$ & $\begin{array}{l}3.70 \\
(2.65-5.17)\end{array}$ & $\begin{array}{l}2.95 \\
(2.07-4.20)\end{array}$ \\
\hline \multicolumn{5}{|l|}{ Schizophrenia } \\
\hline $\begin{array}{l}\text { No ADHD (unaffected } \\
\text { siblings) }\end{array}$ & 1 (REF) & 1 (REF) & 1 (REF) & 1 (REF) \\
\hline ADHD & $\begin{array}{l}5.58 \\
(2.70-11.53)\end{array}$ & $\begin{array}{l}4.48 \\
(2.12-9.48)\end{array}$ & $\begin{array}{l}4.47 \\
(1.95-10.23)\end{array}$ & $\begin{array}{l}3.29 \\
(1.39-7.83)\end{array}$ \\
\hline \multicolumn{5}{|l|}{ Other NAPD } \\
\hline $\begin{array}{l}\text { No ADHD (unaffected } \\
\text { siblings) }\end{array}$ & 1 (REF) & 1 (REF) & 1 (REF) & 1 (REF) \\
\hline ADHD & $\begin{array}{l}4.78 \\
(3.51-6.51)\end{array}$ & $\begin{array}{l}4.32 \\
(3.15-5.93)\end{array}$ & $\begin{array}{l}3.43 \\
(2.39-4.91)\end{array}$ & $\begin{array}{l}2.79 \\
(1.91-4.08)\end{array}$ \\
\hline
\end{tabular}

\footnotetext{
a Adjusted for sex and birth year

b Model I with additional adjustments for ASD.

c Model I with additional adjustments for substance abuse

d Model I with additional adjustments for ASD and substance abuse.
}

risks for NAPD, but this analysis had somewhat limited statistical power. We did not conduct a within-individual comparison between treated and non-treated periods regarding risks for NAPD. Such an approach would be less biased by confounding and likely useful in examining medication related risks for a trigger effect of short psychotic episodes, albeit likely less relevant for schizophrenia or other chronic NAPD. Last, the association between ADHD and NAPD might be overestimated if individuals diagnosed with ADHD have greater awareness about their psychotic symptoms and greater likelihood to be diagnosed with NAPD by the health care services compared to individuals with undiagnosed ADHD.

\subsection{Comparison with other studies}

The results of our study confirm and extend previous studies showing associations between ADHD and NAPD (Hennig et al., 2017; Shyu et al., 2015). A large population-based study of 73,049 individuals with ADHD from Taiwan found a previous diagnosis of ADHD to be a powerful predictor of developing psychosis in young adulthood (Shyu et al., 2015). They found a slightly increased risk for NAPD, but not for schizophrenia, associated with use of methylphenidate among ADHD individuals. However, the study did not examine the usage length of methylphenidate or other types of ADHD medication and did not adjust for background factors. Our study is the first to investigate the use of both stimulant and non-stimulant ADHD medication and the risk for NAPD. We did not find support that stimulants may cause NAPD in ADHD. This is in line with a recent large population-based study with a self-controlled cases series design, which failed to find an association between periods of usage of methylphenidate and incident psychotic episodes in children and adolescents (Man et al., 2016). By contrast, two earlier studies found methylphenidate to increase risk of psychotic symptoms during periods of usage in children (MacKenzie et al., 2016) and to be related to earlier age at onset of psychosis in adults.(Moran et al., 2015) However, these studies were of very small sample sizes ( $n=205$ (Moran et al., 2015) and 141(MacKenzie et al., 2016), respectively) and one was restricted to children of mentally ill parents (MacKenzie et al., 2016). 


\subsection{Interpretation}

Previous studies on the association of ADHD with the risk of NAPD (Hennig et al., 2017; Shyu et al., 2015) have generally yielded strong risk estimates, for example and over 4-fold risk for schizophrenia and an over 5-fold risk for other NAPD in the study from Taiwan outlined above (Shyu et al., 2015). Our study adds that part of the risk for NAPD in ADHD is dependent on comorbid ASD and substance abuse This is consistent with previous studies showing a strong relationship between ASD and NAPD (Selten et al., 2015). It could be that there is stronger common genetic vulnerability between NAPD and autism than between ADHD and NAPD, which is supported by findings in genetic studies (Cross-Disorder Group of the Psychiatric Genomics et al., 2013; Zhao and Nyholt, 2017).

Yet, common susceptibility might still be a pathway linking ADHD and NAPD. This is supported by studies showing associations between most childhood mental disorders, including ADHD, and NAPD (Maibing et al., 2015), indicating a common underlying susceptibility for NAPD and childhood mental disorders. Alternatively, it could be that ADHD-like symptoms are early premorbid signs of psychotic disorders, which are likely to be diagnosed as ADHD. It might also be that altered neurobiology in ADHD, such as dopamine dysregulation (Spencer et al., 2013), also underlies the development of NAPD (Jauhar et al., 2017) and could partly explain the excess psychosis risk in ADHD. Another explanation of the increased risk for NAPD in ADHD could be that ADHD increases the risk of exposure to environmental risk factors for psychosis, such as residential instability, school failure and socioeconomic adversity (Björkenstam et al., 2016).

Further, we found that usage of either type of ADHD medication was associated with higher risk for NAPD. We distinguished between stimulant and non-stimulant medication and found comparable associations with NAPD risk. Indeed, the risk estimates were somewhat higher for non-stimulant than stimulant medication and for shorter than longer usage length of medication. Thus, it is unlikely that ADHD medication, and stimulants in particular, may have a causal effect on the risk for NAPD in ADHD. Although, we cannot entirely rule out this hypothesis, our findings suggest that the factors influencing the psychiatric assessment to treat ADHD with medication, such as the severity of the behavioural and attentional symptoms, the patient's level of functioning, and failure of non-pharmacological treatments may be associated with the risk for NAPD.

Last, we found that substance abuse attenuated the association between ADHD and risk for NAPD. Substance abuse, including drugs and alcohol abuse, is common in ADHD already at an early age (Molina et al., 2013), and $27 \%$ of young adults with ADHD in our study had comorbid substance abuse. Substance abuse may increase risk for psychosis (Buchy et al., 2014), but it may also be an indicator of individuals at risk for psychosis (Carney et al., 2017) and increase exposure to other psychosis risk factors, such as traumatic life events (Spauwen et al., 2006). Whether substance abuse per se increases risk for NAPD is disputed but, nevertheless, it has a positive predictive value and is associated with worse clinical outcomes. Our findings indicate that preventing and/or treating substance abuse in ADHD has the potential to reduce the risk of NAPD in these patients.

\section{Conclusion}

Individuals with ADHD have a markedly increased risk for NAPD and the risk is partly explained by comorbid ASD and/or substance abuse. Among individuals with ADHD, usage of stimulant or non-stimulant medication is associated with higher risk for NAPD, indicating that the clinical symptoms that lead to drug treatment in ADHD may also increase the risk for NAPD. Clinically, efforts should be made to prevent and treat substance abuse in ADHD and to monitor cases comorbid with ASD for the development of psychotic symptoms.

\section{Author contributors}

Dr. Kosidou originated the idea. Dr. E Björkenstam and Dr. Pierce analyzed the data. Drs E Björkenstam and Kosidou wrote the manuscript draft. Dr. Dalman is responsible for the material and general setting of the study. All co-authors contributed to the interpretation of the results and to the writing of the final manuscript.

\section{Role of funding source}

This work was supported by the Swedish Regional agreement on Medical Training and Clinical Research (Grant No. 20170384). Data linkages have also been supported by a grant from the Swedish Research Council (Grant No. 521-2012-2264).

\section{Declaration of competing interest}

On behalf of all authors, the corresponding author states that is no conflict of interest.

Acknowledgement

None.

\section{References}

Bahmanyar, S., Sundstrom, A., Kaijser, M., von Knorring, A.L., Kieler, H., 2013. Pharmacological treatment and demographic characteristics of pediatric patients with attention deficit hyperactivity disorder, Sweden. Eur. Neuropsychopharmacol. 23 (12), 1732-1738.

Biederman, J., Faraone, S.V., 2005. Attention-deficit hyperactivity disorder. Lancet 366 (9481), 237-248

Björkenstam, E., Burström, B., Vinnerljung, B., Kosidou, K., 2016. Childhood adversity and psychiatric disorder in young adulthood: an analysis of 107,704 Swedes. J. Psychiatr. Res. 77, 67-75.

Brodsky, K., Willcutt, E.G., Davalos, D.B., Ross, R.G., 2014. Neuropsychological functioning in childhood-onset psychosis and attention-deficit/hyperactivity disorder. Journal of child psychology and psychiatry, and allied disciplines 55 (7), 811-818.

Buchy, L., Perkins, D., Woods, S.W., Liu, L., Addington, J., 2014. Impact of substance use on conversion to psychosis in youth at clinical high risk of psychosis. Schizophr. Res. 156 $(2-3), 277-280$.

Capusan, A.J., Bendtsen, P., Marteinsdottir, I., Larsson, H., 2019. Comorbidity of adult ADHD and its subtypes with substance use disorder in a large population-based epidemiological study. J. Atten. Disord. 23 (12), 1416-1426.

Carney, R., Yung, A.R., Amminger, G.P., Bradshaw, T., Glozier, N., Hermens, D.F., Hickie, I.B. Killackey, E., McGorry, P., Pantelis, C., Wood, S.J., Purcell, R., 2017. Substance use in youth at risk for psychosis. Schizophr. Res. 181, 23-29.

Colizzi, M., Murray, R., 2018. Cannabis and psychosis: what do we know and what should we do? Br. J. Psychiatry 212 (4), 195-196.

Cross-Disorder Group of the Psychiatric Genomics, C, 2013. Genetic relationship between five psychiatric disorders estimated from genome-wide SNPs. Nat. Genet. 45 (9), 984-994.

Giacobini, M., Medin, E. Ahnemark, E., Russo, L.J., Carlqvist, P., 2018. Prevalence, patient characteristics, and pharmacological treatment of children, adolescents, and adults diagnosed with ADHD in Sweden. J. Atten. Disord. 22 (1), 3-13.

Hennig, T., Jaya, E.S., Koglin, U., Lincoln, T.M., 2017. Associations of attention-deficit/ hyperactivity and other childhood disorders with psychotic experiences and disorders in adolescence. Eur Child Adolesc Psychiatry 26 (4), 421-431.

Jauhar, S., Nour, M.M., Veronese, M., Rogdaki, M., Bonoldi, I., Azis, M., Turkheimer, F. McGuire, P., Young, A.H., Howes, O.D., 2017. A test of the transdiagnostic dopamine hypothesis of psychosis using positron emission tomographic imaging in bipolar affective disorder and schizophrenia. JAMA Psychiatry 74 (12), 1206-1213.

Larsson, H, Ryden, E, Boman, M., Långström, N., Lichtenstein, P., Landen, M, 2013. Risk of bipolar disorder and schizophrenia in relatives of people with attention-deficit hyperactivity disorder. Br. J. Psychiatry 203 (2), 103-106.

Leitner, Y., 2014. The co-occurrence of autism and attention deficit hyperactivity disorde in children - what do we know? Front. Hum. Neurosci. 8, 268.

MacKenzie, L.E., Abidi, S., Fisher, H.L., Propper, L., Bagnell, A., Morash-Conway, J., Glover J.M., Cumby, J., Hajek, T., Schultze-Lutter, F., Pajer, K., Alda, M., Uher, R., 2016. Stimulant medication and psychotic symptoms in offspring of parents with mental illness. Pediatrics 137 (1).

Maibing, C.F., Pedersen, C.B., Benros, M.E., Mortensen, P.B., Dalsgaard, S., Nordentoft, M. 2015. Risk of schizophrenia increases after all child and adolescent psychiatric disorders: a Nationwide study. Schizophr. Bull. 41 (4), 963-970.

Man, K.K., Coghill, D., Chan, E.W., Lau, W.C., Hollis, C., Liddle, E., Banaschewski, T. McCarthy, S., Neubert, A., Sayal, K., Ip, P., Wong, I.C., 2016. Methylphenidate and the risk of psychotic disorders and hallucinations in children and adolescents in a large health system. Transl. Psychiatry 6 (11), e956.

Molina, B.S., Hinshaw, S.P., Eugene Arnold, L., Swanson, J.M., Pelham, W.E., Hechtman, L, Hoza, B., Epstein, J.N., Wigal, T., Abikoff, H.B., Greenhill, L.L., Jensen, P.S., Wells, K.C. Vitiello, B., Gibbons, R.D., Howard, A., Houck, P.R., Hur, K., Lu, B., Marcus, S., Group, M.T.A.C., 2013. Adolescent substance use in the multimodal treatment study of attention-deficit/hyperactivity disorder (ADHD) (MTA) as a function of childhood ADHD, random assignment to childhood treatments, and subsequent medication. J Am. Acad. Child Adolesc. Psychiatry 52(3), 250-263. 
Moran, L.V., Masters, G.A., Pingali, S., Cohen, B.M., Liebson, E., Rajarethinam, R.P., Ongur, D., 2015. Prescription stimulant use is associated with earlier onset of psychosis. J. Psychiatr. Res. 71, 41-47.

Mosholder, A.D., Gelperin, K., Hammad, T.A., Phelan, K., Johann-Liang, R., 2009. Hallucinations and other psychotic symptoms associated with the use of attention-deficit/ hyperactivity disorder drugs in children. Pediatrics 123 (2), 611-616.

Polanczyk, G.V., Willcutt, E.G., Salum, G.A., Kieling, C., Rohde, L.A., 2014. ADHD prevalence estimates across three decades: an updated systematic review and meta-regression analysis. Int. J. Epidemiol. 43 (2), 434-442.

Selten J.P. Lundberg M, Rai, D. Magnusson, C, 2015. Risks for nonaffective psychotic disorder and bipolar disorder in young people with autism spectrum disorder: a population-based study. JAMA Psychiatry 72 (5), 483-489.

Shyu, Y.C., Yuan, S.S., Lee, S.Y., Yang, C.J., Yang, K.C., Lee, T.L., Wang, L.J., 2015. Attentiondeficit/hyperactivity disorder, methylphenidate use and the risk of developing schizophrenia spectrum disorders: a nationwide population-based study in Taiwan. Schizophr. Res. 168 (1-2), 161-167.

Skoglund, C., Chen, Q., Franck, J., Lichtenstein, P., Larsson, H., 2015. Attention-deficit/ hyperactivity disorder and risk for substance use disorders in relatives. Biol. Psychiatry $77(10), 880-886$.

Spauwen, J., Krabbendam, L., Lieb, R., Wittchen, H.U., van Os, J., 2006. Impact of psychological trauma on the development of psychotic symptoms: relationship with psychosis proneness. Br. J. Psychiatry 188, 527-533.
Spencer, T.J., Biederman, J., Faraone, S.V Madras, B.K., Bonab, A.A, Dougherty, D.D. Batchelder, H., Clarke, A., Fischman, A.J., 2013. Functional genomics of attentiondeficit/hyperactivity disorder (ADHD) risk alleles on dopamine transporter binding in ADHD and healthy control subjects. Biol. Psychiatry 74 (2), 84-89.

Thomas, R. Sanders, S. Doust, J., Beller, E. Glasziou, P. 2015. Prevalence of attentiondeficit/hyperactivity disorder: a systematic review and meta-analysis. Pediatrics 135 (4), e994-1001.

Vitiello, B., Perez Algorta, G., Arnold, L.E., Howard, A.L., Stehli, A., Molina, B.S., 2017. Psychotic symptoms in attention-deficit/hyperactivity disorder: an analysis of the MTA database. J. Am. Acad. Child Adolesc. Psychiatry 56 (4), 336-343.

Zetterqvist, J., Asherson, P., Halldner, L., Långström, N., Larsson, H., 2013. Stimulant and non-stimulant attention deficit/hyperactivity disorder drug use: total population study of trends and discontinuation patterns 2006-2009. Acta Psychiatr. Scand. 128 (1), 70-77

Zhao, H., Nyholt, D.R., 2017. Gene-based analyses reveal novel genetic overlap and allelic heterogeneity across five major psychiatric disorders. Hum. Genet. 136 (2), 263-274.

Zuvekas, S.H., Vitiello, B., 2012. Stimulant medication use in children: a 12-year perspective. Am. J. Psychiatry 169 (2), 160-166. 